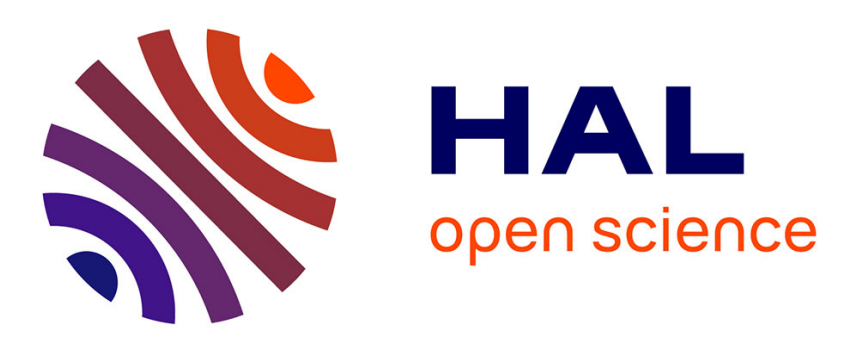

\title{
Classification of chemicals into emission-based impact categories: a first approach for equiprobable and site specific conceptual frames
}

Anne Ventura

\section{- To cite this version:}

Anne Ventura. Classification of chemicals into emission-based impact categories: a first approach for equiprobable and site specific conceptual frames. International Journal of Life Cycle Assessment, 2011, 16 (2), pp.148-158. 10.1007/s11367-010-0242-x . hal-00959074

\section{HAL Id: hal-00959074 https://hal.science/hal-00959074}

Submitted on 13 Mar 2014

HAL is a multi-disciplinary open access archive for the deposit and dissemination of scientific research documents, whether they are published or not. The documents may come from teaching and research institutions in France or abroad, or from public or private research centers.
L'archive ouverte pluridisciplinaire HAL, est destinée au dépôt et à la diffusion de documents scientifiques de niveau recherche, publiés ou non, émanant des établissements d'enseignement et de recherche français ou étrangers, des laboratoires publics ou privés. 


\title{
Classification of chemicals into emission- based impact categories: a first approach for equiprobable and site specific conceptual
}

\section{frames}

\author{
Anne Ventura \\ Université de Nantes, Laboratoire Central des Ponts et Chaussées \\ Tel : (33) 240845616 \\ Fax : (33) 240845993 \\ e-mail : anne.ventura@lcpc.fr
}

\section{Abstract}

Purpose

The classification step is systematically neglected in the calculation of LCIA indicators: for several direct contribution of one pollutant to several impact categories, the distribution between these impact categories is not accounted. The proposed approaches of non-redundant classification are based on the probability that an emitted substance and its chemically degraded forms are involved into several environmental impacts.

Methods

Two types of repartitions are examined in this paper: i) one, called equiprobable classification, based on identical probability of contributions to several impact categories, and ii) and one, called zone classification based. Both methods are based on a classification coefficient alpha and require categorization of chemical pathways (reactive, suspensive, direct, indirect). The first method, the equiprobable classification, is a quick method that allows avoiding multiple counting of pollutants. The second method, the zone classification method is based on two steps: i) the first step requires defining an impacted zone around the source, inside which the emitted chemicals are expected to majorly diffuse or spread; ii) in the second step, the score of the chemical is set according to the occurrence of the chemical target inside the impacted zone.

Results

Both methods are applied on a case study of NOx emissions in Paris. Results highlight big differences (33\% to $47 \%$ ) when using or not the classification coefficient. Coefficients calculated using equiprobable or zone classifications are of the same order of magnitude except for indirect contributions.

Discussion 
The zone classification method is compared to other site specific LCA methods. The choices of impacted zone and of chemical targets are discussed with the aim to meeting paradoxical constraints: local parameters must be sufficiently detailed in the majority of cases, but generic enough to avoid time consuming researches. The availability of data is also discussed as well as the possibility to include indirect impacts into the environmental system.

Conclusions

The conceptual frame suggested for classification of pollutants into emission-based impact categories, is a first approach for a scientific question that was raised in the 90's. equiprobable classification is easy to apply but not entirely satisfying from a physical and chemical background. Zone classification relies upon the specificity of emission compartments, and occurrence of chemical targets in the impacted zone. It still needs improvements. It has important consequences in terms of data collection, system boundaries, and only practise will show its actual feasibility.

Keywords: classification, life cycle impact assessment, emission-based impact categories, site specific lca 


\section{Introduction}

The Life Cycle Impact Assessment is a step of the Life Cycle Assessment that is dedicated to translate a huge amount of environmental inventory flows into their expected environmental effects using a reduced number of indicators. According to (Consoli et al. 1993), the first step that consists of distributing pollutants into various impact categories is called "classification". This classification step is systematically neglected in the calculation of LCIA indicators (equation (1)): for several direct contribution of one pollutant to several impact categories, the distribution between these impact categories is not accounted.

$I=\sum_{i} C_{i} \cdot m_{i}$

where $I$ is the environmental indicator (kg equivalent to the reference substance), $C_{i}$ is the contribution coefficient of the inventory flow $i$ to the impact category as an equivalent to the reference substance, and $m_{i}$ is the mass of the inventory flow $i$.

As one mass of pollutant is entirely affected to each of the direct impact categories, this comes down to multiply the mass of one pollutant by the number of impact categories, and thus overestimating the actual indicator value. Furthermore, if one pollutant indirectly contributes to an impact category because it is chemically transformed, it is not included into indicators calculation. In that case, the indicator value is underestimated. This classification problem has recently been highlighted as still unresolved by Reap et al. (2008).

Udo de Haes (1996) had already discussed of this classification step and defined the notions of parallel, serial, indirect and combined impacts. Based on this initial approach (Udo de Haes, 1996), the present study aims at defining a methodological frame for non-redundant classification, based on the probability that an emitted substance and its chemically degraded forms are involved into several environmental impacts. Two types of repartitions are examined in this paper: i) one, called equiprobable classification, based on identical probability of contributions to several impact categories, and ii) and one, called zone classification, that has already been studied in a first attempt (Ventura et al, 2007) and (Sayagh et al, 2009), based on territorial conditions and that is formalized in this paper.

\section{General principles of classification}

Compared to the classical LCA indicator, an additional classification coefficient $\alpha_{i}$ for the inventory flow $i$ is defined (see equation (2)). This coefficient yields, for a given inventory flow, the mass proportion contributing to a given impact category. The new indicator equation including the $\alpha_{i}$ coefficient is detailed below: 
where $\alpha_{i}$ is the classification coefficient of the inventory flow $i$ to the impact category (no unit).

A Distribution coefficient is defined by the equation below:

$D_{i}=\sum_{i} \alpha_{i}$

Several types of contributions of one pollutant to an impact category are defined and schematized on Figure 1.

The contribution of the pollutant $i$ to one impact category is defined as reactive when the contribution implies that the pollutant $i$ is transformed by a chemical reaction.

The contribution of the pollutant $i$ to one impact category is defined as suspensive when the contribution does not imply the chemical transformation of the molecule.

The contribution of the pollutant $i$ to one impact category is defined as direct when the contribution is directly issued from the pollutant $i$.

The contribution does not imply the chemical transformation of the molecule.

The contribution of the pollutant $i$ to one impact category is defined as indirect, when the impact is due to a new pollutant $j$ produced after a first contribution being reactive or suspensive. For example, the contribution of methane to photochemical ozone formation is reactive because $\mathrm{CH}_{4}$ is chemically degraded, whereas its contribution to the greenhouse effect is suspensive because it is not chemically degraded. In that case, the $\mathrm{CH}_{4}$ molecule is still available for a chemical reaction, i.e. $\mathrm{CH}_{4}$ can react with another organic compound under the action of ultraviolet rays, and produce photochemical ozone. This contribution can be considered as successive to the first one.

Another example is airborne emitted $\mathrm{NH}_{3}$ : it contributes to odour and toxicity as direct contributions, it is chemically transformed in $\mathrm{HNO}_{3}$ in the atmosphere and thus successively contributes to acidification, and once in soil and water, contributes to eutrophication, successively to acidification.

Several rules need to be respected for the $D_{i}$ values, depending on the chemical behaviour of pollutant $i$ when contributing to each impact category.

Generalizing this concept conducts to the following rules:

- for direct and reactive contributions of pollutant $i$ to several impact categories

$$
D_{i}^{\text {reactive,direct }}=\sum_{i} \alpha_{i}^{\text {reactive, direct }}=1
$$

- If there is any indirect or suspensive contributions issued from pollutant $i$ :

$$
D_{i}^{\text {total }}=D_{i}^{\text {reactive, direct }}+D_{i}^{\text {suspensive, } \text { indirect }}>1
$$

The following parts of the paper will examine various procedures for calculating $\alpha_{i}$ values. 


\section{Equiprobable classification}

The purpose the equiprobability classification procedure is to avoid multiple counting of pollutants.

Let's consider that pollutant $i$ has direct reactive contributions to one or several impact categories numbered 1 to $n$, and direct suspensive contributions to one or several impact categories numbered $n+1$ to $m$. With the equiprobable procedure, $\alpha_{i}^{\text {direct }}$ has the same value whatever is the impact category. It is calculated by the following equation:

$\alpha_{i}^{\text {direct }}=\frac{1}{n}$

And then, the Distribution coefficient is calculated by:

$D_{i}^{\text {direct }}=1+\frac{(m-n)}{n}$

In that case of indirect contributions, the "no impact" contribution is considered equiprobable and one is added to the denominator. If pollutant $i$ is degraded in pollutants $j_{1 \text { to } k}$ for $k$ indirect impact categories, then:

$\alpha_{i \rightarrow j}^{\text {indirect }}=\frac{\alpha_{i}^{\text {direct }}}{k+1}$

To show an application of the method, let's take again the example of methane.

The $\mathrm{CH}_{4}$ molecule has one direct suspensive contribution $(n=1)$ to the greenhouse effect, because the molecule is not chemically degraded: $\alpha_{C H_{4}}^{\text {direct(GWP) }}=1$ according to equation (4). Thus, $\mathrm{CH}_{4}$ is still available for chemical reaction, and can contribute to produce photochemical ozone. However, the contribution to photochemical oxidation is considered successive to the contribution to the greenhouse effect. According to equation (6), and with $k=1$, then $\alpha_{C H_{4}}^{\text {indirect }(P O C P)}=\frac{\alpha_{C H_{4}}^{\text {direct }(G W P)}}{k+1}=\frac{1}{2}$.

Using $k=1$ at the denominator in equation (6), means that the whole mass of methane is not classified in the photochemical oxidation. This indeed takes into account that the fate and transport of the methane is not known, and thus may not undergo photochemical oxidation.

\section{Zone classification}

Another methodology can be proposed to calculate these coefficients accounting local conditions parameters. The zone classification method is based on two steps: i) the first step requires defining an impacted zone around the source, inside which the emitted chemicals are expected to majorly diffuse or spread; ii) in the second step, the score of the chemical is set according to the occurrence 
of the chemical target inside the impacted zone. The chemical target is defined as the event that will simultaneously provoke the degradation of a pollutant and the environmental effect. Thus, the chemical target does not exist for suspensive contributions, but only for reactive contributions. The following parts detail the method for calculating classification coefficients. Values are suggested to show the application of the method: for impacted zones in relationship with the type emission (Table 1), and for chemical targets inside impacted zone (Table 2). The choices of impacted zones and chemical targets are however very rough, and are further examined in the discussion part of this article.

\section{Case of direct and reactive contributions}

For each emitted pollutant that has a direct contribution to several environmental impacts, the emissions conditions are analyzed by filling Table 1 . The local emission conditions will gather rough information concerning the transport of the pollutant and the probability to reach the chemical target concerned by each impact category.

A score, noted $\sigma_{i, k}$, is affected to each case (Table 1). The value of $\sigma_{i, k}$ can be defined as follow:

- $\sigma_{i, k}^{\min }=0$ if there is no chemical target in the impacted zone,

- $\sigma_{i, k}^{\max }=1$ if chemical targets are at their maximum known value $N_{k}$ in the impacted zone or if the impacted zone is the Earth (i.e. global impacts such as climate change or stratospheric ozone layer depletion).

$$
\begin{aligned}
& -\sigma_{i, k}=\frac{n_{k}}{N_{k}} \\
& n_{k}<N_{k} \text { in the impacted zone. }
\end{aligned}
$$

if the number of chemical targets is

For the impact category $k$, with $1<k<K$, and the pollutant $i$, the total score is defined as:

$$
s_{i, k}=\sum_{\text {all compartments }} \sigma_{i, k}
$$

the emission compartments being those defined in Table 1.

Then the classification coefficient $\alpha_{i, k}^{\text {direct }}$ can be calculated as follows:

$$
\alpha_{i, k}^{\text {direct }}=\frac{s_{i, k}}{\sum_{k=1}^{K} s_{i, k}}
$$

\section{Case of indirect or suspensive contributions}

The calculation of classification coefficients for indirect contributions will follow the same rule as for the direct ones, but they will be calculated from the corresponding $\alpha_{i, k}^{\text {direct }}$. 
Let's consider the contribution of pollutant $j$ to the several impact categories $1<k_{2}<K_{2}$, after being initially produced by pollutant $i$ through a reactive contribution to the impact category $k_{1}$ (route A on Figure 1). The score of pollutant $j$ is calculated as a direct contribution to impact categories $k_{2}$ but considering the zone of the impact category $k_{1}$ initially affected by pollutant $i$. $\sigma_{j, k_{2}}=\sigma_{i, k_{1}} \cdot \frac{n_{k_{2}}}{N_{k_{2}}}$

Then, the total score is calculated by:

$$
s_{j, k_{2}}=\sum_{\text {all compartments }} \sigma_{j, k_{2}}
$$

Then the indirect contribution of pollutant $i$ is calculated as follows:

$\alpha_{i \rightarrow j, k_{2}}^{\text {indirect }}=\alpha_{i, k_{1}}^{\text {direct }} \cdot s_{j, k_{2}}$

The case of direct but suspensive contribution concerns environmental impacts caused by a molecule but not by a chemical reaction, therefore there is no chemical target. The greenhouse gases have such a contribution to the climate change impact category. Whatever is the type of air emission (Table 1) greenhouse gases will contribute to the climate change impact category. In that case, the score $\sigma_{j, C C I}=1$.

\section{Suggestions for chemical targets}

Table 2 presents possible reference values for chemical targets that can be used to calculate scores (see equations (8) and (11)).

For toxicity, the involved pollutant is degraded by human metabolism. Thus, the indicator for chemical target has been chosen as the presence of human being in the impacted zone. Then, population density is proposed as a reference. The maximal existing value is the population density of Cairo city: 35,420 people $/ \mathrm{km}^{2}$.

For ecotoxicity, the involved pollutant is degraded when in contact with any living being. Thus, the percentage of natural or cultivated surface area in the impacted zone, have been chosen as the chemical target indicator.

For photochemical ozone formation, the involved pollutant is degraded under the action of ultraviolet rays, and sometimes only if simultaneously in contact with other chemical species (synergistic effect). However, sunrays are necessary and are thus the limiting factor. Therefore, the sunshine duration appears to be a quite acceptable indicator of the chemical target. The maximal existing value is the number of hours in a year: 8,760 hr/yr. Values concerning impacted zones of Table 2 have been collected from (Meteo France, 2009).

For acidification, the involved pollutant is expected to release $\mathrm{H}^{+}$ions mainly when in contact with water molecules in the atmosphere. This corresponds to inverse conditions compared to the 
occurrence of photochemical ozone formation. Thus, hours without sunshine can be taken as a reference. The maximal existing value is again the number of hours in a year: 8,760 hr/yr.

For aquatic eutrophication, the pollutants are consumed by plants and microorganisms that will proliferate in surface waters. Thus, the percentage of surface water area in the impacted zone can be chosen as an indicator for the chemical target. The maximum value is therefore $100 \%$, and the values concerning impacted zones of Table 2 have been crossed from several sources (OSE, 2008), (OSE, 2009) and (Wikipedia, 2009).

\section{Application example on NOx emissions}

As an example, both classification methods are applied to stack and diffuse emissions of nitrogen oxides NOx, occurring in Paris.

Figure 2 presents the nitrogen biogeochemical paths, and contributions of human activities.

NOx are mainly produced by human activities, and especially by combustion processes, where $\mathrm{N}_{2}$ is oxidized into $\mathrm{NO}$ and $\mathrm{NO}_{2}$. mainly by thermal decomposition of $\mathrm{N}_{2}$ (Miller and Bowman, 1989):

$\mathrm{N}_{2}+\mathrm{O}^{\bullet} \rightarrow \mathrm{N}^{\bullet}+\mathrm{NO}$

$\mathrm{N}^{\bullet}+\mathrm{O}_{2} \rightarrow \mathrm{NO}+\mathrm{O}^{\bullet}$

$\mathrm{N}^{\bullet}+{ }^{\bullet} \mathrm{OH} \rightarrow \mathrm{NO}+\mathrm{H}^{\bullet}$

Other chemical pathways (not detailed in this paper) can also produce NO: fuel NO (Tomita, 2001) or prompt NO (Fenimore, 1971). Whatever the pathway is, $\mathrm{NO}$ is rapidly converted in $\mathrm{NO}_{2}$ in the atmosphere:

$\mathrm{NO}+\mathrm{RO}_{2} \rightarrow \mathrm{NO}_{2}+1 / 2 \mathrm{HO}_{2}+\mathrm{R}$

$\mathrm{NO}_{2}$ can directly contribute to several impact categories.

In presence of water in the atmosphere, $\mathrm{NO}_{2}$ will form nitric acid, and cause an acidification impact:

$3 \mathrm{NO}_{2}+\mathrm{H}_{2} \mathrm{O} \rightarrow 2 \mathrm{HNO}_{3}+\mathrm{NO}$

In the presence of ultraviolet rays, $\mathrm{NO}_{2}$ can lead to photochemical ozone formation:

$\mathrm{NO}_{2}+\mathrm{uv} \rightarrow \mathrm{O}^{\bullet}+\mathrm{NO}^{\bullet}$

$\mathrm{O}^{\bullet}+\mathrm{O}_{2} \rightarrow \mathrm{O}_{3}$

$\mathrm{NO}_{2}$ also directly contributes to toxicity when breathed by human population.

$\mathrm{NO}_{2}$ can also indirectly contribute to several impact categories: $\mathrm{HNO}_{3}$ produced by equation (15)

will produce $\mathrm{NO}_{3}{ }^{-}$in contact with water, and thus contribute to terrestrial and aquatic eutrophication.

$\mathrm{HNO}_{3}+\mathrm{H}_{2} \mathrm{O} \rightarrow \mathrm{H}^{+}+\mathrm{NO}_{3}^{-}$

Furthermore, $\mathrm{O}_{3}$ produced by equations (16a) and (16b) will contribute to toxicity.

Results shown in Table 3 highlight that big differences of final indicators value would be found when using or not the classification coefficient. With an equiprobable classification, the 
contributions of NOx molecules to photochemical ozone formation, acidification and toxicity is respectively $33 \%, 33 \%$ and $47 \%$ of an actual value without classification.

The coefficients calculated using equiprobable or zone classifications are in the same order of magnitude except for indirect contributions, where the equiprobable method leads to an overestimated result.

\section{Discussion}

The discussion is organized in three parts. In a first part, the zone classification is compared with existing LCA localised approaches. In the second part, the two steps of zone classification are discussed. In a third part, the feasibility of both equiprobable and zone classifications is examined.

\section{Zone classification and existing LCA-localised approaches}

In the literature, various sets of impact categories were defined corresponding to midpoints, endpoints, and damages for each generic areas of protection (Bare and Gloria, 2008).

Some authors have been interested by assessing spatial differentiated indicators for resources issues (Brent 2004) and (Raugei and Ulgiati 2009). Concerning emissions of chemical substances, other studies have been conducted in order to integrate spatial differentiation in LCA methods with the aim of calculating endpoint indicators. They all require transports models of pollutants in the various compartments of the environment; these have been reviewed by Mackay and Reid (2008). These models are often completed by the inclusion of chemical fate of pollutants, especially to account for pollutants involved into human toxicity and ecosystem toxicity (Huijbregts et al, 2001), (Huijbregts et al, 2005). A scientific consensus between modellers has raised from the UNEP/SETAC Life Cycle initiative (Rosenbaum et al. 2008) leading to the USEtox model. Some general remarks can be made concerning these various models:

- they are all focused on long term distribution of pollutant in the environment,

- thus, they are all focused on persistent pollutants, and their effect on toxicity and ecotoxicity,

- they deeply examine the distribution of one pollutant in the different compartments of the environment,

- the complexity of those methods mainly relies upon the number of considered compartments (Mackay and Reid, 2008).

However, many pollutants do no enter these models because they are not persistent: they are more or less rapidly chemically transformed, and, because of their chemical transformation, they can indirectly contribute to several other impact categories.

The inclusion of geographical specified data has already been proposed by several authors (Potting 1994), (Huijbregts et al, 2001), (Huijbregts et al, 2003), (Webster et al, 2004), (Mackay and Reid, 2008). The main difference between those methods and the zone classification are schematised on Figure 3 and Figure 4.

For existing methods (Figure 3), indicators calculations are performed from a pollutant mass that is aggregated for the whole environmental system, wherever is the emission spot. Then, the distribution of pollutant is considered between environmental compartments, they will depend on transport scenarios. However, the environmental compartments are not geographically defined (air, 
water, soil, sediments...). The aggregation of one pollutant mass over the whole system before classification indeed conducts to lose the specificity of the geographical details.

For the zone allocation method (Figure 4), although the transport of pollutant presented in this paper is roughly integrated, by considering a perimeter of impacted zone, the geographical specificities are kept until the ending step of impact characterisation. In case of specific needs, the level of accuracy for the transport of pollutants can be increased. Furthermore, territorial environmental issues are considered in the indicator calculation.

Potting and Hauschild (2005) introduced the notion of site factor that characterizes the sensitivity of an impacted zone area to a given environmental impact, because they mention that "...it is commonly recognised that the calculated contributions, except for the global impacts, could be in poor accordance with the expected occurrence of actual impacts". Although site specific data are required, the objective of zone classification is different: it is dedicated to assess the occurrence of chemical targets in an impacted zone, as a previous step to the indicator calculation.

\section{The two steps of zone classification}

The use of site specific data in LCA is a particularly paradoxical challenge. Local parameters must be sufficiently detailed to be scientifically relevant in the majority of cases, but generic enough to avoid time consuming researches, as LCA are generally multi-sites studies. The types and values suggested in Table 1 (types and size of impacted zones) and Table 2 (chemical targets) are a first attempt to fulfil these contradictory demands.

\section{Defining the impacted zone}

Table 1 gives suggestions for emission compartments that could be related to the dimension, and size of the impacted zone. For airborne emissions, two types of emissions are distinguished: "stack" and "other" emissions. This distinction between stack emissions and others is linked to the design principles of industrial exhaust equipments (ASHRAE, 2007). Industrial stacks (height and diameter) are designed to ensure large dispersions of pollutants: it must be sufficient to avoid exposure of immediate neighbourhood to high concentrations of toxic compounds. The geometrical characteristics of industrial stacks are generally defined according to the expected gas flue (average velocity), the analysis of surrounding environment (presence of other stacks, buildings or natural obstacles), and of prevailing wind (main directions and velocity). General design rules are generally incorporated into environmental regulations, i.e. (JORF 2008) in France. Thus, one can consider that stack emissions will preferentially be dispersed and transported on long distances. The term "other" emissions correspond to emissions sources that are not designed for large dispersions. They can be engine exhausts, diffuse, fugitive emissions... The emitted pollutants can be considered to be dispersed and transported on short distances, although in some particular cases, it could also be transported on long distances, i.e. favourable physical and wind configurations and/or persistent pollutants (Bennett et al. 2001).

For water emissions, the pollutant transport zone will depend on the type of receiving water. For stagnant water, the dispersion can be considered limited to the pool or lake surface area. The depth could also be considered, as well as sediments. For quick current water, the dispersion can be 
considered to follow the stream bed on a distance mainly depending on the rate of flow. For ocean water, the dispersion can be considered on a surface (or depth) depending on the tide amplitude. For soil emissions, the pollutant can be estimated to almost not disperse.

In actual environmental impacts of chemical pollution, environmental transport distances and transfers between compartments, is much more complex. Suggestions featuring in Table 1 could be refined using existing transport models like the one suggested by McKone and Bennett (2003), if a good knowledge of local parameters is available. This degree of complexity could especially be relevant for persistent chemicals: complexity of their transport is partly linked to the amount of time between the emission into the environment and the chemical reaction.

\section{Choice of the chemical target}

Table 2 suggests chemical targets to account inside the impact zone, in relationship with the emission-based impact categories.

The population density has been chosen as the chemical target for toxicity.

For ecotoxicity, the chemical target has been chosen as the percentage of wild nature or cultivated surface area inside the impacted zone. Actually, the presence of any living thing does not indicate an effect because some ecotoxicants are very specific to certain types of species but not others. If suitable data are available chemical targets could be refined using more detailed data on specific ecosystems, i.e. in accordance with the ones used by (Huijbregts et al, 2001): fresh water, marine and terrestrial.

For photochemical ozone creation, the annual hours of sunshine duration have been chosen as the chemical target, because it is the limiting factor, without which the chemical reaction would not occur.

For acidification, the choice of annual duration hours without sunshine for a chemical target is disputable: acidification can occur during sunshine by means of dry deposition followed by reaction with any humid surfaces. In fact, this chemical target is only relevant for airborne emissions, for which acid molecules can be in competition with photochemical oxidation. For water compartment, the score is logically maximal, and it can also be considered maximum for soil in most of the cases, as the acid molecule will release $\mathrm{H}^{+}$ions whenever in contact with living organisms or rainwater.

\section{Feasibility of both classification methods}

The equiprobable classification only requires knowing the conditions of emissions for each substance (see Table1): in the available ILCD guidance for life cycle inventories (EPLCA 2008), sufficient details about emission conditions are already forecasted. This method is thus well adapted to general LCA studies, where pollutants are aggregated upon their emission spots. It is mainly useful to avoid multiple counting of one pollutant mass and can rapidly be included in existing tools. However, this first approach can not be entirely satisfying because it is not justified by physical and chemical backgrounds. 
The zone classification is more satisfying from this last requirement, but the method needs several types of specific data: emission compartments, the knowledge of emission sites, and the occurrence of chemical targets.

In existing databases, the inventory data in LCA are usually expressed in amounts per functional unit and, in principle, nothing is known about the source. When examining SPOLD exchange format (Singhofen et al 1996) geographical information is already available, although not very accurate (only the country code is required), but this type of information could be completed by geographical coordinates. The ILCD guidance (EPLCA 2008) for inventories seams also appropriate to integrate the information.

Concerning emission compartments, the knowledge does exist at the very first step of data collection: measurement methods are very different considering the emission compartment. As an example for airborne emissions, stack emissions require particular measurements systems whereas diffuse emissions from a stockpile require emission models (US-EPA, 2010). Thus, inventory data could contain suitable information, if producers care to collect and properly aggregate them.

The question of indirect contributions, accounting for chemical transformation of pollutants is also important, because it introduces a new complexity in the impact assessment. In the case of one pollutant leading several successive chemical reactions, each product being itself a pollutant, how far the number of iterations should be conducted? In the same manner, in the case of an emitted chemical $i$ that has not direct and reactive contribution, but that is chemically transformed into a pollutant $j$, having itself a contribution, should the indirect or suspensive contributions be accounted (in this particular case: $D_{i}^{\text {total }}=D_{i}^{\text {suspensive, indirect }} \leq 1$ )? In fact, this possibility changes the limit of the system. Although there can be no general answer to be give to this question, for the moment, one iteration seams a reasonable track to explore, as the example dealt in Table 3 , shows very weak values of the classification coefficient for indirect impacts.

\section{Conclusion}

The principle of using a classification coefficient for distributing a mass of pollutant between several impact categories appears relatively simple and is scientifically justified. This conceptual frame suggests classification as a previous step to indicator calculations. It can thus be combined with any type of emission-based indicators for LCIA, from midpoint to endpoint or damage indicators.

Two different methods, based on a classification coefficient, are presented to solve this problem. Both proposed methods require for the calculation of the coefficient value, a categorization of chemical pathways (reactive, suspensive, direct, indirect). The first method, the equiprobable classification, is a quick method that allows avoiding multiple counting of pollutants and is well adapted to general LCA studies, where pollutants are aggregated upon their emission spots. It could rapidly be included in existing tools.

The second method, the zone classification method, is related to territorial aspects. This method requires the definition of a chemical target. It appears helpful by accounting the effect of pollutants in the territory they are emitted, whereas actual methods consider environmental 
compartments wherever the pollution occurs. Applying this new method drives to gather detailed information about each location spots of involved producing processes. The classification method is dedicated to differentiate environmental pressures between varying places all over the world, but it does not contribute to assess actual environmental impacts. Udo de Haes (1996) defined LCA as “...primarily a tool for resource conservation and pollution prevention”, and for this reason "....all emissions are regarded as relevant on the basis of their intrinsic hazard characteristics". Although using geographical parameters, the classification step only allows differentiating, by a probabilistic approach, environmental pressures from one place to another. The conceptual frame for classification is still in accordance with the general LCA philosophy promoted by ISO 14040/44 that the impacts in LCIA are potential, not real ones.

However, the choice of the impacted zone is important and it is thus necessary to find general rules that are scientifically relevant in the majority of cases. The suggested rules (Table 1) are still to refine, especially in the case of persistent pollutants. In the same manner, chemical targets are suggested in the present article but may be refined; this essentially depends on the availability of geo-localised data. For example, in practice it could be difficult in an LCA to include the population density since so many different locations would be included. However, some similar approaches have been recently suggested, using GIS and dynamic map gridding tools, concerning toxic pollutant sources and population density targets (Jolliet et al. 2010).

The possibility to include indirect impacts can conduct to shift away the environmental system boundaries, taking into account the chemical fate of pollutants.

Finally, another important consequence of such a method is that indicators are not anymore mathematically independent from one another, although it reflects a chemical reality. The further use of indicators results into a multicriteria decision aiding process should take this new fact into consideration.

The feasibility of zone classification as for other region-specific methods will depend on the specific LCA study and has to be decided in the "Goal \& Scope". It is clearly not applicable in the case of generic LCA, where production processes are not related to sites and suppliers of one product are interchangeable. The feasibility is also related to availability of data. In most databases, it is in general not possible to trace back the sites, data are most frequently averages. In comparative LCAs, the question of potential asymmetries between compared cases will be an important one.

\section{References}

ASHRAE, 2007. American Society of Heating, Refrig. And Air-Cond. Eng., Chapter 44, "Building Air Intake and Exhaust Design", ASHRAE Applications Handbook, Inc., Atlanta.

Bare J.C., Gloria T.P., 2008. Environmental impact assessment taxonomy providing comprehensive coverage of midpoints, endpoints, damages, and areas of protection. Journal of Cleaner Production 16:1021-1035.

Bennett D.H., Scheringer M., McKone T.E., Hungerbühler K., 2001. Predicting long-range transport: a systematic evaluation of two multimedia transport models. Environ. Sci. Technology, 35(6):1181-1189. 
Brent, A., 2004. A life cycle impact assessment procedure with resource groups as areas of protection. International Journal of LCA 9(3):172-179.

Consoli, F., D. Allen, I. Boustead, J. Fava, W. Franklin, A.A. Jensen, N. de Oude, R. Parrish, D. Postlethwaite, B. Quay, J. Siéguin and B. Vigon 1993. (Eds.). Guidelines for life cycle assessment. A code of practice. Brussels (Belgium),Society of Environmental Toxicology and Chemistry - Europe and North America.

EPLCA, 2008. European Platform on LCA, International Reference Life Cycle Data System (ILCD) Handbook, ILCD reference elementary flows table, http://lct.jrc.ec.europa.eu/eplca/deliverables/international-reference-life-cycle-datasystem-ilcd-handbook, last update 18 december 2008.

Fenimore C.P., 1971. Formation of nitric oxide in premixed hydrocarbon flames, 13th Symp. Combustion Pittsburg, pp. 373-380.

FAO, 2008. Global Forest Resources Assessment, Food and Agriculture Organization of the United Nations, http://www.fao.org/forestry/41256/fr/, last update 26 may 2008.

Huijbregts M.A.J., Thissen U., Guinée J.B., Jager T., Kalf D., van de Meent D., Ragas A.M.J., Wegener Sleeswijk A., Reijnders L., 2001. Priority assessment of toxic substances in life cycle assessment. Part I: Calculation of toxicity potentials for 181 substances with the nested multi-media fate, exposure and effects model USES-LCA. Chemosphere 41:541-573.

Huijbregts M.A.J., Lundi S., McKone T.E., van de Meent D., 2003. Geographical scenario uncertainty in generic fate and exposure factors of toxic pollutants for life-cycle impact assessment. Chemosphere 51:501-508.

Huijbregts M.A.J, Struijs J., Goedkoop M., Heijungs R., Hendriks A.J., van de Meent D., 2005. Human population intake fractions and environmental fate factors of toxic pollutants in life cycle impact assessment. Chemosphere 61(10):1495-1504.

Jolliet O.J. , Wannaz C., Fantke P., 2010. Multiscale, Multimedia modelling to compare local and global life cycle impacts on human health. Abstract LCO4C-3, $20^{\text {th }}$ SETAC Europe annual meeting, Seville (Spain), 23-27 May.

JORF, 2008. Arrêté du 2 décembre 2008 modifiant l'arrêté du 25 juillet 1997 relatif aux prescriptions générales applicables aux installations classées pour la protection de l'environnement soumises à déclaration sous la rubrique ${ }^{\circ} 2910$ (Combustion). Journal Officiel de la République Française $n^{\circ} 291$ du 14 décembre 2008.

Mackay D., Reid L., 2008. Local and distant residence times of contaminants in multicompartment models. Part I: A review of the theoretical basis. Environmental Pollution 156:1196-1203.

McKone T.E., Bennett D.H., 2003. Chemical-specific representation of air-soil exchange and soil penetration in regional multimedia models. Environ. Sci. Technol. 37(14):3123-3132.

MeteoFrance, 2009. http://france.meteofrance.com

Miller J.D. and Bowman C.T., 1989. Mechanism and modelling of nitrogen chemistry in combustion, Progress in Energy and Combustion Science 15:287-338.

OSE, 2008. Ressources en eaux - eaux de surface. Observatoire et Statistiques de l'Environnement du Ministère de l'Ecologie, de l'Energie, du Développement Durable et de la Mer, http://www.ifen.fr/acces-thematique/eau/ressources-en-eau/les-eaux-de-surface.html, last update November 2008.

OSE, 2009. Observatoire national des zones humides - les zones humides en France. Observatoire et Statistiques de l'Environnement du Ministère de l'Ecologie, de l'Energie, du Développement Durable et de la Mer, http://www.ifen.fr/accesthematique/territoire/zones-humides/onzh/les-zones-humides-en-france.html, last update June 2009.

Potting J., 1994. Spatial Differentation in Life Cycle Impact Assessment. PhD Utrecht University, 177 pp. NWS-E-2000-02

Potting J., Hauschild M., 2005. Background for spatial differentiation in LCA impact assessment The EDIP2003 methodology. Environmental Project No. 996 2005, Danish Ministry of 
the Environment. www2.mst.dk/Udgiv/publications/2005/87-7614-581-6/pdf/87-7614582-4.pdf.

Reap J., Roman F., Duncan S., Bras B., 2008. A survey of unresolved problems in life cycle assessment. Part II: impact assessment and interpretation. International Journal of LCA 13:374-388.

Raugei M., Ulgiati S., 2009. A novel approach to the problem of geographic allocation of environmental impact in Life Cycle Assessment and Material Flow Analysis. Ecol. Ind. 9:1257-1264.

Reid L., Mackay D., 2008. Local and distant residence times of contaminants in multicompartment models. Part II: Application to assessing environmental mobility and longtime range atmospheric transport. Environmental Pollution 156:1182-1189.

Rosenbaum R.K., Bachmann T.M., Gold L.S., Huijbregts M.A.J., Jolliet O., Juraske R., Koehler A., Larsen H.F., MacLeod M., Margni M., McKone T., Payet J., Schuhmacher M., van de Meent D., Hauschild M., 2008. USEtox - the UNEP/SETAC toxicity model: recommended characterisation factors for human toxicity and freshwater ecotoxicity in life cycle impact assessment. International Journal of LCA 13:532-546.

Sayagh S., Ventura A., Hoang T., François D., Jullien A., 2009. Sensitivity of the LCA allocation procedure for BFS recycled into pavement structures. Resources, Conservation and Recycling 54:348-358.

Singhofen A, Hemming C, Weidema B, Grisel L, Bretz R, de Smet B, Russell D., 1996. Life Cycle Inventory Data: Development of a common format. International Journal of LCA 1(3):171-178.

Tomita A., 2001. Suppression of nitrogen oxides emission by carbonaceous reductants, Fuel Process. Technol. 71:53-70.

Udo de Haes H.A., 1996. Part I - Discussion of general principles and guidelines for practical use in Towards a methodology for life cycle impact assessment Ed. Udo de Haes H.A., published by SETAC Europe.

US-EPA, 2010. Technology Transfer Network Clearinghouse for Inventories \& Emissions Factors, Emissions Factors \& AP 42, Compilation of Air Pollutant Emission Factors, http://www.epa.gov/ttnchie1/ap42/

Ventura A., Monéron P., Jullien A., 2008. Environmental impact of a binding course pavement section, with asphalt recycled at varying rates - use of Life Cycle Methodology. Journal of Road Materials and Pavement Design, Vol.9 Special Issue EATA 2008, pp. 319-338.

Webster E., Mackay D., Di Guardo A., Kane D., Woodfine D., 2004. Regional differences in chemical fate model outcome. Chemosphere 55:1361-1376.

Wikipedia, 2009. Liste des plus grands lacs et étangs de France, http://fr.wikipedia.org/wiki/Liste_des_plus_grands_lacs_et_\%C3\%A9tangs_de_France 